\title{
Effects of exposure time and co-existing organic compounds on uptake of atrazine from nutrient solution by rice seedlings (Oryza sativa L.)
}

\author{
Yu-Hong Su ${ }^{\text {a,b,*, }}$, Yong-Guan Zhu ${ }^{\text {a }}$, Ai-Jun Lin ${ }^{\text {a }}$, Xu-Hong Zhang ${ }^{\mathrm{a}}$ \\ ${ }^{a}$ Research Center for Eco-environmental Sciences, Chinese Academy of Sciences, 18 Shuangqing Road, Beijing 100085, China \\ ${ }^{\mathrm{b}}$ Chemistry Department, Xinjiang University, Urumqi 830046, China \\ Received 17 August 2005; received in revised form 12 June 2006; accepted 28 June 2006 \\ Available online 1 July 2006
}

\begin{abstract}
Root uptake of atrazine (ATR) by rice seedlings (Oryza sativa L.) from nutrient solution was investigated with exposure periods of 48, 96, and $240 \mathrm{~h}$. A similar ATR uptake was carried out with two co-existing organic compounds (o-chlorophenol (CP) and 2,4-dichlorophenol (DCP)) with $48 \mathrm{~h}$ exposure. In contact with the seedlings, the ATR level in nutrient solution decreased sharply during the early exposure and then reached relatively steady levels after $48 \mathrm{~h}$. It was observed that the ATR levels within whole seedlings approached the estimated equilibrium partition limits in about $48 \mathrm{~h}$, according to the partition-limited model utilizing the measured plant water and organic matter contents and the ATR partition coefficients with whole seedlings. However, when roots and shoots were consisted separately, the detected ATR levels in roots were lower than estimated equilibrium limit while the levels in shoots exceeded the equilibrium limit. The data with roots suggested the occurrence of rapid ATR degradation in roots. The results with shoots are intrinsically consistent with the suggested complex formation of ATR with free metal ions in shoots. The ATR levels in roots and shoots varied to a moderate extent when the seedlings were exposed to different levels of ATR-CP-DCP mixtures. The variation results presumably from the interference of coexisting CP and DCP and the phytotoxicity of the mixed chemicals.
\end{abstract}

(C) 2006 Elsevier B.V. All rights reserved.

Keywords: Atrazine; Plant uptake; Exposure time; Rice seedlings; Bioconcentration factor

\section{Introduction}

Crops are subject to contamination by pesticides and organic wastes via root and/or foliage contact [1-3]. The need to understand how the various parameters affect the plant uptake has led to a series of investigations on the process [4,5]. Recent studies show that organic chemicals in water enter plants largely via passive process [6-8]. In contrast, the plant uptake of electrolytes is mediated by their electrical potentials and complex-formation powers [7,9].

ATR, a carcinogen suspect, is one of the most extensively applied pesticides in agriculture. Thus, ATR and its degradation products are detected in soil, surface water, and groundwater [10-11]. In neutral pH, ATR persists for a long time in soils and groundwater (half-life of atrazine is about 398-742 days in neutral soils and 10000 days in water at pH 7) [12-14], although banned for use in some countries, ATR remains as a most sig-

\footnotetext{
* Corresponding author.

E-mail address: syh73112000@yahoo.com.cn (Y.-H. Su).
}

nificant water pollutant [11]. ATR may be toxic to amphibian species even at very low doses [15]. Understanding ATR transport and transformation in environmental systems is essential to assessing the ecological risk posed by ATR.

In plant uptake of organic chemicals from water, many assumed that the concentrations in roots and water reach equilibrium after a certain root-exposure time $[4,16]$. However, the equilibrium state has not always been confirmed by an unequivocal criterion. It is thus important to study plant-uptake kinetics with a method/model that defines the true equilibrium state. The quasi-equilibrium partition model of Chiou et al. [6] enables one to bridge the kinetic uptake with the equilibrium state. The model relates the chemical level in plants (or in a plant part) at a given time to the source level in external water by

$C_{\mathrm{pt}}=\alpha_{\mathrm{pt}} C_{\mathrm{w}}\left[f_{\mathrm{pw}}+f_{\mathrm{pom}} K_{\mathrm{pom}}\right]$

where $C_{\mathrm{pt}}$ is the chemical concentration in plants on a freshweight basis and $C_{\mathrm{w}}$ is the concentration in external water (or soil water); $f_{\mathrm{pw}}$ and $f_{\text {pom }}$ are the respective weight fractions for plant water and plant organic matter; $K_{\text {pom }}$ the chemical parti- 
tion coefficient between plant organic matter and plant water; $\alpha_{\mathrm{pt}}(\leq 1)$ is the quasi-equilibrium factor, the ratio of chemical levels in plant water and external water at a specific point in time. When $\alpha_{\mathrm{pt}}=1$, the levels in plants and external water are at equilibrium; when $\alpha_{\mathrm{pt}}$ is $<1$, it indicates the extent in plants toward the equilibrium limit. The ratio of $C_{\mathrm{pt}}$ to $C_{\mathrm{w}}$ at is called the "bioconcentration factor" (BCF). At the point of equilibrium, the BCF is equal to $\left[f_{\mathrm{pw}}+f_{\mathrm{pom}} K_{\mathrm{pom}}\right]$.

In fact, different organic compounds usually coexist in the actual polluted soils or surface waters, while only few studies have been carried out about effects of coexisting organic compounds on plant uptakes. $O$-dichlorophenol and 2,4-dichlorophenol usually enter environment with the waste water drained by chemical plants in china, which make them become a typical coexisting organic compounds with atrazine in the farmland. Thus, this study presents the uptake of ATR by rice seedlings from nutrient solution, the plant uptake as a function of uptake time, and the effect of coexisting compounds ( $o$-dichlorophenol and 2,4-dichlorophenol) on the ATR uptake in order to investigate the interaction of organic compounds with different properties. The results were analyzed according to Eq. (1).

\section{Materials and methods}

\subsection{Preparation of rice seedlings}

Rice seeds (Oryza sativa cv. Giyou-1) were disinfected in $30 \% \mathrm{H}_{2} \mathrm{O}_{2}$ (w/w) solution for $10 \mathrm{~min}$, followed by thorough washing with de-ionized water. The seeds were germinated in moist perlite. After 3 weeks, uniform seedlings were selected and transplanted to PVC pots $(7.5 \mathrm{~cm}$ diameter and $14 \mathrm{~cm}$ high, one plant per pot) containing $500 \mathrm{ml}$ of a nutrient solution. The compositions of nutrient solutions were listed in Table 1 . The nutrient solution was a modification of Long Ashton formula after Zhu et al. [17] with the $\mathrm{pH}$ maintained at 5.0 using $0.1 \mathrm{M}$ $\mathrm{KOH}$ or $\mathrm{HCl}$ solution [18]. The nutrient solution was changed once a week. The seedlings were allowed to grow in nutrient solution for three weeks before being used for uptake studies.

\subsection{Treatments with atrazine}

Chemicals, such as $\mathrm{K}_{2} \mathrm{SO}_{4}, \mathrm{NH}_{4} \mathrm{NO}_{3}, \mathrm{CaCl}_{2}$, used in plant uptake studies were all of analytical grade; ATR was provided by Chem. Service, Inc. (China). Purities of all chemicals are more than $98 \%$. In experiment 1 , the rice seedlings were exposed to nutrient solutions with different ATR at 0,2, 4, 6, 8 and $10 \mathrm{mg} \mathrm{l}^{-1}$

Table 1

Compositions of nutrient solutions

\begin{tabular}{llll}
\hline Compounds & Concentration & Compounds & Concentration \\
\hline $\mathrm{NH}_{4} \mathrm{NO}_{3}$ & $1.7 \mathrm{mM}$ & $\mathrm{H}_{3} \mathrm{BO}_{4}$ & $5.0 \mu \mathrm{M}$ \\
$\mathrm{KH}_{2} \mathrm{PO}_{4}$ & $4.0 \mathrm{mM}$ & $\mathrm{ZnSO}_{4}$ & $0.5 \mu \mathrm{M}$ \\
$\mathrm{K}_{2} \mathrm{SO}_{4}$ & $0.7 \mathrm{mM}$ & $\mathrm{CuSO}_{4}$ & $0.5 \mu \mathrm{M}$ \\
$\mathrm{CaCl}_{2}$ & $1.3 \mathrm{mM}$ & $\mathrm{MnSO}_{4}$ & $2.5 \mu \mathrm{M}$ \\
$\mathrm{MgSO}_{4}$ & $0.5 \mathrm{mM}$ & $\mathrm{Na}_{2} \mathrm{MoO}_{4}$ & $0.2 \mu \mathrm{M}$ \\
$\mathrm{Fe}(\mathrm{III})-\mathrm{EDTA}$ & $50.0 \mu \mathrm{C}$ & $\mathrm{CoSO}_{4}$ & $0.1 \mu \mathrm{M}$ \\
\hline
\end{tabular}

without $o$-chlorophenol (CP) and 2,4-dichlorophenol (DCP) for $48 \mathrm{~h}$. In experiment 2 , the seedlings were exposed to mixtures of ATR, CP, and DCP, with initial CP/DCP/ATR concentrations (in $\mathrm{mg}^{-1}$ ) set at 10/5/2, 20/10/4, 40/20/6, 80/40/8, and 160/80/10. In experiment 3 , the seedlings were exposed to $50-\mathrm{ml}$ nutrient solution with ATR at 5.0, 10.0 and $20.0 \mathrm{mg} \mathrm{l}^{-1}$ in brown glass bottle, the open areas between the cap and the rice seedlings were sealed with sponge. At selected times, $0.2 \mathrm{ml}$ of nutrient solution was removed and extracted with hexane to determine the ATR concentration. The solution was weighed and the loss of water by plant transpiration was replenished to maintain the total solution volume at ca. $50 \mathrm{ml}$. The change in ATR concentration due to the sampling loss was corrected.

In experiment 4 , the seedlings were exposed to nutrient solutions with different (initial) ATR concentrations at 0, 2.5, 5.0, and $10.0 \mathrm{mg} \mathrm{l}^{-1}$ for $96 \mathrm{~h}$. In experiment 5 , the seedlings were exposed to nutrient solutions with (initial) ATR at 0, 0.6, 1.2, $2.0,3.0$ and $4.0 \mathrm{mg} \mathrm{l}^{-1}$ for $240 \mathrm{~h}$. In experiment 6 , the containers with no rice seedlings were filled with nutrient solutions containing ATR at $0,2.5,5.0$, and $10.0 \mathrm{mg} \mathrm{l}^{-1}$ to the same volume as in experiment 5 , the open area were sealed with sponge. The containers with rice seedlings in experiments 1 and 2 were weighed five times everyday to measure the water loss by plant transpiration, and the same amounts of nutrient solution were replenished. The ATR concentration in nutrient solution was measured at 48, 96 and $240 \mathrm{~h}$ intervals to register the ATR loss during the uptake experiment. In experiments 4-6, the containers with rice seedlings were weighed twice everyday and the loss of solution was replenished. In all experiments, each treatment was conducted with four replicates. The experiments were carried out in a controlled environment with a $14 \mathrm{~h}$ light period (260-350 $\mu \mathrm{mol} \mathrm{m}^{-2} \mathrm{~s}^{-1}$ ) at temperatures of $25^{\circ} \mathrm{C}$ day and $20^{\circ} \mathrm{C}$ night. The relative humidity was $70 \%$. The control seedling at the end of the each experiment were sectioned into roots and shoots and weighed. Portions of the samples were freeze-dried $\left(-45^{\circ} \mathrm{C}\right)$ to determine the respective plant water contents $\left(f_{\mathrm{pw}}\right)$ and organic-matter contents $\left(f_{\mathrm{pom}}\right)$.

In experiment-1, experiment-2, experiment-4 and experiment-5, the nutrient solutions containing different levels of given contaminants were held by a series of identical PVC (polyvinylchloride) cylinders. The cylinder was fitted with a PVC septum $(7.5 \mathrm{~cm}$ in diameter and $0.5 \mathrm{~cm}$ in thickness) with a hole drilled at its center $(1.5 \mathrm{~cm}$ in diameter), through which the plant shoots extended into the outside air space. The section of shoots passing through the septum hole was wrapped with sponge sheets to minimize the open space. This design prevented direct water evaporation from nutrient solution into the external air when the seedlings were in place. Hence, the mass of water transpired through plant shoots could be determined accurately by the net weight change of the nutrient solution and plants.

\subsection{Water transpiration rate}

Amounts of water transpired by plants over the $48 \mathrm{~h}$ period were determined based on the cumulated weight losses of the plant-solution systems by measuring their weight changes at 
1-3 h intervals during 7:00 a.m. and 11:00 p.m. After each measurement, the amount of water lost by plant transpiration was replenished with fresh nutrient solution to maintain the total solution volume at a nearly constant level of ca. $500 \mathrm{ml}$. By this method, the error in measured water transpiration was minimized. It also enabled one to quickly detect the change in plant transpiration rate when the plant growth was affected by the contaminant phototoxicity. From the cumulated water-loss weights and measured fresh-plant weights after $48 \mathrm{~h}$ exposure, plant transpiration rates $(G)$ (as g water/g fresh plant weight) were then computed.

\subsection{Analysis of atrazine}

Seedling samples were first sectioned into roots and shoots. The sectioned plant parts were rinsed with distilled water four times to remove residual ATR on plant surfaces, wiped with tissue paper, and immediately weighed. The samples were then homogenized using a mortar and pestle, and then extracted using an ultrasonic crusher machine with $40 \mathrm{ml}$ of mixed methanol and water $(1: 1, \mathrm{v} / \mathrm{v})$. The liquid phase was filtrated and collected. The samples were then extracted three times with $10 \mathrm{ml}$ of fresh mixed solvents. The liquid portions from all extractions were combined and extracted with $20 \mathrm{ml}$ of mixed petroleum ether and dichloromethane $(6.5: 3.5, \mathrm{v} / \mathrm{v})$. Supernatants of the mixedsolvent phase were eluted through anhydrous $\mathrm{Na}_{2} \mathrm{SO}_{4}$ columns and collected. This procedure was repeated four times. The eluates were combined, concentrated into a small volume (1-2 ml) using a rotary evaporator (Senco, China) with a gentle stream of dry nitrogen, solvated again with $30 \mathrm{ml}$ petroleum ether, and extracted three times with $20 \mathrm{ml}$ of acetonitrile. The acetonitrile fractions were combined, concentrated, and evaporated off. The residues were solvated with petroleum ether and cleaned with a Florisil column. The concentrations of ATR in extracts were analyzed with an Agilent 6820 gas chromatograph with a ${ }^{63} \mathrm{Ni}$ electron capture detector (ECD) using a HP-5 capillary column $(0.32 \mathrm{~mm} \times 30 \mathrm{~m}, 0.25 \mu \mathrm{m}$ film thickness). Peak areas of ATR were quantified with external standards for quantifying ATR concentrations. The average recoveries of ATR in controls were $83.9-96.6 \%(n=5)$ for the plant samples.

\subsection{Data analysis}

Analysis of the data variance (ANOVA) was performed using Genstat 6.0 for Windows on a personal computer (NAG Ltd., UK). Two-way analysis of variance was carried out on the ATR uptake data.

\section{Results and discussion}

\subsection{Plant biomass}

Average biomasses of both roots and shoots in each experiment were listed in Table 2. Biomasses of both roots and shoots exposed to mixtures of contaminants were significantly less than those exposed to single contaminants. Similarly, the root and shoot biomasses exposed to lower ATR level and to a longer
Table 2

Biomasses ( $\mathrm{g}$ dry matter) of rice seedlings in different series of experiments (mean \pm S.E.)

\begin{tabular}{lllll}
\hline Exposure time & Contaminant & Shoots & Roots & $N^{\mathrm{a}}$ \\
\hline 48h (experiment 1) & ATR & $1.81 \pm 0.07$ & $0.66 \pm 0.03$ & 24 \\
48 h (experiment 2) & ATR + CP + DCP & $1.31 \pm 0.08$ & $0.50 \pm 0.02$ & 20 \\
96h (experiment 4) & ATR & $1.84 \pm 0.09$ & $0.69 \pm 0.03$ & 16 \\
240h (experiment 5) & ATR & $3.41 \pm 0.13$ & $1.34 \pm 0.06$ & 24
\end{tabular}

${ }^{\text {a }} N$ are the number of rice seedlings.

contact time (experiment 5) were far greater than those exposed to higher ATR level and to a shorter contact time (experiments 1 and 3 ).

\subsection{Fundamental plant and contaminant parameters}

Root and shoot water contents $\left(f_{\mathrm{pw}}\right)$ of the rice seedlings, obtained from water losses upon drying of fresh control samples, are 0.905 and 0.852 , respectively. Determined by differences, the organic-matter contents $\left(f_{\text {pom }}\right)$ are 0.095 and 0.148 for roots and shoots, respectively. The sorption isotherms of ATR with dry roots or shoots were constructed using the dry sectioned samples in contact with a series of nutrient solutions containing different quantities of ATR [19]. From the isotherms, the respective $K_{\text {pom }}$ values with seedling roots and shoots are determined. Experimental $f_{\mathrm{pw}}, f_{\mathrm{pom}}$, and $K_{\mathrm{pom}}$ values with seedling roots and shoots enable the respective $\left[f_{\mathrm{pw}}+f_{\text {pom }} K_{\text {pom }}\right]$ terms in Eq. (1) to be quantified, as listed in Table 3 . The resulting $\left[f_{\mathrm{pw}}+f_{\mathrm{pom}} K_{\mathrm{pom}}\right]$ values are then used to determine for the respective $\alpha_{\mathrm{pt}}$ values of ATR with (live) roots and shoots, according to Eq. (1), in various ATR-uptake experiments.

\subsection{Live plant uptake: ATR alone}

The ATR concentrations in roots and shoots of rice seedlings were significantly higher than in external nutrient solution. The results show close linear relations between ATR concentrations in roots/shoots and nutrient solution, as shown in Fig. 1. The ATR uptake is higher in shoots than in roots. The linear relationship between ATR levels in plant tissues and nutrient solutions (Fig. 1) indicates that the plant ATR uptake is relatively independent of the plant biomass. This effect suggests that the ATR concentration in plants reaches a steadystate level with respect to the external concentration in nutrient solution.

Table 3

Measured partition coefficients $\left(K_{\text {pom }}\right)$ of ATR between dry roots/shoots of rice seedlings and water and respective $\left[f_{\mathrm{pw}}+f_{\mathrm{pom}} K_{\mathrm{pom}}\right]$ and $f_{\mathrm{pom}} K_{\mathrm{pom}} / f_{\mathrm{pw}}$ values with fresh roots and shoots

\begin{tabular}{llll}
\hline Plant part & $K_{\text {pom }}( \pm$ S.E. $)$ & {$\left[f_{\mathrm{pw}}+f_{\mathrm{pom}} K_{\mathrm{pom}}\right]^{\mathrm{a}}$} & $f_{\mathrm{pom}} K_{\mathrm{pom}} / f_{\mathrm{pw}}$ \\
\hline Roots & $36.8( \pm 2.8)$ & 4.40 & 3.87 \\
Shoots & $20.1( \pm 1.7)$ & 3.83 & 3.49 \\
\hline
\end{tabular}

a Based on the measured organic-matter contents $\left(f_{\text {pom }}\right)$ of 0.095 and 0.148 , respectively, with fresh plant roots and shoots; the respective water contents $\left(f_{\mathrm{pw}}\right)$ with roots and shoots are 0.905 and 0.852 . 


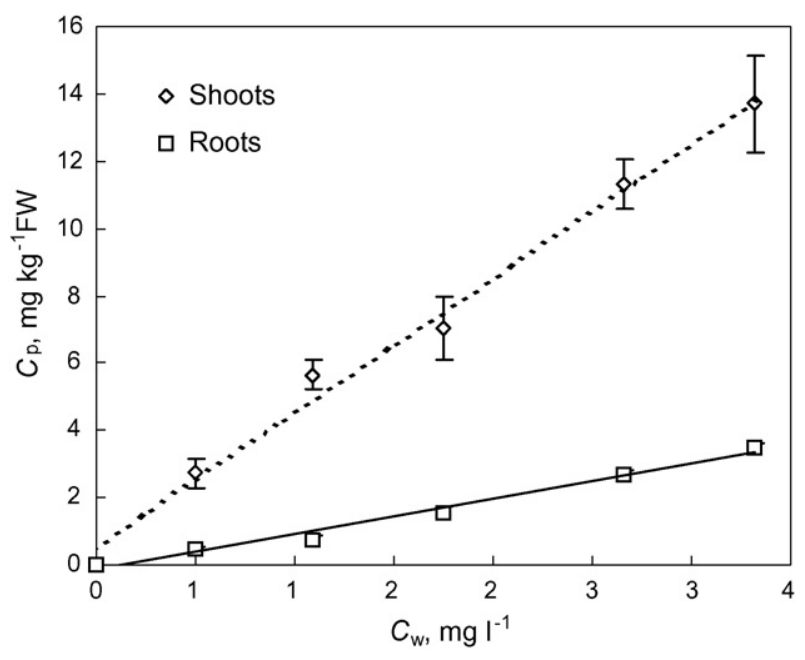

Fig. 1. Uptake of ATR by rice seedlings as a function of ATR concentration in nutrient solution (experiment 5). Each point is the mean of four replicates. Error bars represent S.E.

There have been few studies comparing the contaminant levels in different plant parts with respect to external levels, as most plant-uptake studies have been conducted with single rather than mixed contaminants. In this report we examine the extents to equilibrium of ATR uptake by roots and shoots of rice seedlings in the absence and presence of $\mathrm{CP}$ and DCP as coexisting chemicals, with the uptake data analyzed by the quasi-equilibrium model (Eq. (1)). The calculated $\alpha_{\mathrm{pt}}$ values for ATR under various system settings are also listed in Table 4.

However, when the ATR data with seedling roots and shoots were analyzed separately according to their compositions, the calculated ATR $\alpha_{\mathrm{pt}}$ values with roots were only 0.3, i.e., onethird the equilibrium limit. On the other hand, the calculated $\alpha_{\mathrm{pt}}$ values with roots exceeded 1 . The results suggest that ATR was metabolized rapidly in seedling roots while engaged in specific binding in shoots. Martin et al. [20] and Meng and Carper [21] showed that certain metal ions, such as $\mathrm{Ca}^{2+}, \mathrm{Mg}^{2+}, \mathrm{Pb}^{2+}$, $\mathrm{Zn}^{2+}, \mathrm{Cd}^{2+}$, and $\mathrm{Cu}^{2+}$, bind effectively with both monomeric and dimeric ATR to form both anhydrous and hydrated complexes. This complex formation of ATR with metal ions is attributed to the strong electron-donating power of ATR.

Once ATR entered the rice seedlings through roots, it distributed itself through plant xylem into shoot tissues. In shoots, ATR could then engage in complex formation with active metal ions (e.g., $\mathrm{Ca}^{2+}$ and $\mathrm{Mg}^{2+}$ ) in excess of its partition with shoots [19]. The formation of relatively stable ATR-bound residues would enhance the accumulation of ATR by seedling shoots. The observation that ATR $\alpha_{\mathrm{pt}}$ values with roots, shoots and whole seedlings in experiment 5 (with $240 \mathrm{~h}$ exposure) are less than those in experiment 1 ( $48 \mathrm{~h}$ exposure) and experiment 4 (96h exposure) resulted likely from the dilution effect of the plant growth. With no other coexisting organic compounds, the BCF and $\alpha_{\mathrm{pt}}$ values of ATR at low levels are largely independent of the ATR level in nutrient solution, based on the results being given in Table 4.

\subsection{Effects of exposure time on live plant uptake}

Results from experiment 6 indicated that the ATR concentration in nutrient solution without plants decreased by less than $2 \%$ during a 10-day period. Thus, the decrease of ATR concentrations in nutrient solution with different exposure periods in experiments $1-5$ could be attributed to plant uptake and transformation (e.g., volatilization and metabolism). ATR concentrations in nutrient solution as a function of uptake time are shown in Fig. 2. The fast initial uptake of ATR caused a sharp drop in its concentration in nutrient solution. After a $10 \mathrm{~h}$ uptake, the concentration in nutrient solution decreased only gradually with time. The trend of ATR uptake by rice seedlings is similar to that found in a previous report [22].

In ATR-alone systems, the $\alpha_{\mathrm{pt}}$ values with whole seedlings were reasonably close to 1 after $48-96 \mathrm{~h}$ exposure, suggesting that the levels in plants were near the equilibrium limits. This finding concurs with a previous report [23] and with the ATR kinetic uptake with time in experiment 3.

Table 4

$\mathrm{BCF}$ and $\alpha_{\mathrm{pt}}^{*}$ of ATR with rice seedlings in experiments with and without CP and DCP

\begin{tabular}{|c|c|c|c|c|}
\hline System setting & Plant part & $C_{\mathrm{w}}\left(\mathrm{mg} \mathrm{l}^{-1}\right)$ & $\mathrm{BCF}$ & $\alpha_{\mathrm{pt}}^{*}$ \\
\hline & Roots & $5.5-9.5$ & $1.64 \pm 0.03$ & $0.39 \pm 0.01$ \\
\hline $\mathrm{ATR}+\mathrm{CP}+\mathrm{DCP} / 48 \mathrm{~h}$ & Shoots & $5.5-9.5$ & $2.99 \pm 0.38$ & $0.80 \pm 0.10$ \\
\hline & \multirow{2}{*}{ Whole seedlings } & $1.0-3.5$ & $2.32 \pm 0.19$ & $0.57 \pm 0.05$ \\
\hline & & $5.5-9.5$ & $2.60 \pm 0.27$ & $0.64 \pm 0.07$ \\
\hline ATR alone $/ 48 \mathrm{~h}$ & Whole seedlings & $1.5-8.5$ & $3.89 \pm 0.14$ & $0.96 \pm 0.03$ \\
\hline \multirow{3}{*}{ ATR alone/96h } & Roots & $2.0-8.0$ & $1.30 \pm 0.18$ & $0.31 \pm 0.04$ \\
\hline & Shoots & $2.0-8.0$ & $5.53 \pm 0.02$ & $1.48 \pm 0.01$ \\
\hline & Whole seedlings & $2.0-8.0$ & $4.32 \pm 0.07$ & $1.06 \pm 0.02$ \\
\hline ATR alone $/ 240 \mathrm{~h}$ & Roots & $0.5-3.5$ & $0.92 \pm 0.06$ & $0.22 \pm 0.01$ \\
\hline
\end{tabular}




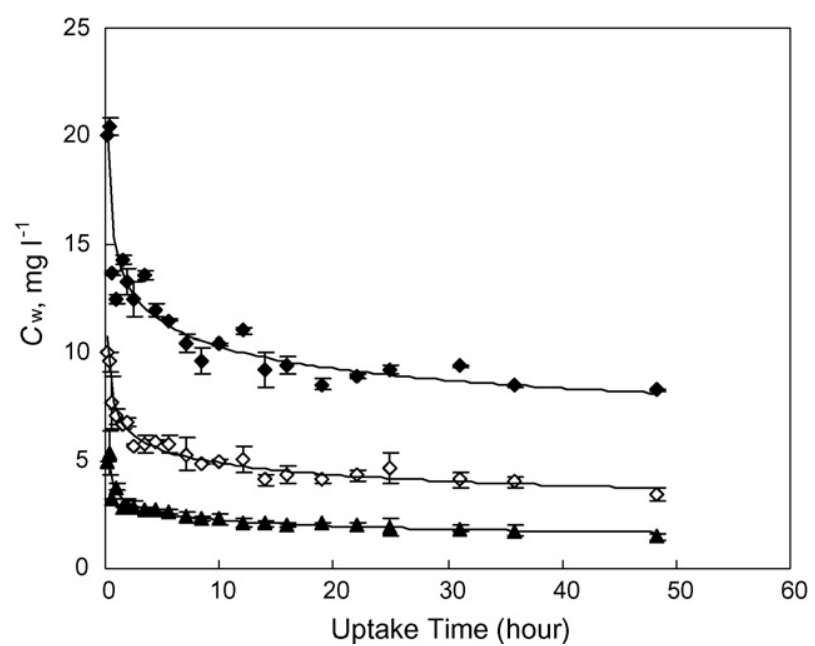

Fig. 2. Change in ATR concentrations in nutrient solution with uptake time (experiment 3). Each point is the mean of four replicates. Error bars represent S.E.

\subsection{Plant transpiration rate}

Control plants showed a relatively transpiration rate $(G)$ at about $8.5 \mathrm{~g}$ water per gram of the fresh plant weight. The change in water transpiration rate with the contaminant level is shown in Table 5. Addition of ATR alone at $2 \mathrm{mgl}^{-1}$ to solution reduced the rate to about $6 \mathrm{~g} \mathrm{~g}^{-1}$; at ATR $=10 \mathrm{mg} \mathrm{l}^{-1}$, the rate dropped to about $5 \mathrm{~g} \mathrm{~g}^{-1}$. At low mixed CP-DCP-ATR levels $\left(10 / 5 / 2\right.$ to $20 / 10 / 4$ in $\left.\mathrm{mg} \mathrm{l}^{-1}\right)$, the amount of water transpired decreased by a small extent to $7.9-7.2 \mathrm{~g} \mathrm{~g}^{-1}$ (relative to $8.5 \mathrm{~g} \mathrm{~g}^{-1}$ for the control species), and the plant growth was inhibited only slightly by the mixed contaminants relative to control plants. The presence of CP and DCP at low concentrations decreased the toxicity of ATR to rice roots and reduced the ATR transformation in roots and shoots. At mixed CP-DCP-ATR levels of 40, 20, and $6 \mathrm{mg}^{-1}$, respectively, the plant water transpiration decreased sharply to $3.7 \mathrm{~g} \mathrm{~g}^{-1}$, and the transformation of atrazine in roots and shoots increased sharply.

Table 5

Relations between transpiration rates $(G)$ of rice seedlings and initial mixed contaminant levels in solutions $\left(C_{\mathrm{w}}^{0}\right)$ to which the roots were exposed ${ }^{\mathrm{a}}$

\begin{tabular}{|c|c|c|c|c|c|}
\hline \multirow{2}{*}{\multicolumn{3}{|c|}{$\begin{array}{l}\text { In mixed-contaminant system } \\
C_{\mathrm{w}}^{0}\end{array}$}} & \multicolumn{3}{|c|}{ In single-contaminant system } \\
\hline & & & \multirow[t]{2}{*}{$G$} & \multirow{2}{*}{$\begin{array}{l}C_{\mathrm{w}}^{0} \\
\text { ATR }\end{array}$} & \multirow[t]{2}{*}{$G$} \\
\hline CP & DCP & ATR & & & \\
\hline \multicolumn{6}{|c|}{ Control plants } \\
\hline 0 & 0 & 0 & 8.50 & 0 & 8.50 \\
\hline \multicolumn{6}{|c|}{ Exposed plants } \\
\hline 10 & 5 & 2 & 7.92 & 2 & 5.96 \\
\hline 20 & 10 & 4 & 7.29 & 4 & 5.43 \\
\hline 40 & 20 & 6 & 3.71 & 6 & 5.24 \\
\hline 80 & 40 & 8 & 5.21 & 8 & 4.54 \\
\hline 160 & 80 & 10 & 4.94 & 10 & 4.42 \\
\hline
\end{tabular}

${ }^{\text {a }} G$ : mass of water transpired per unit fresh weight of the rice seedlings $\left(\mathrm{g} \mathrm{g}^{-1}\right)$; $C_{\mathrm{w}}^{0}$ : initial contaminant concentration in solution $\left(\mathrm{mg} \mathrm{l}^{-1}\right)$.

\subsection{Live plant uptake: ATR mixed with CP and DCP}

Results from experiment 2 showed that the presence of CP and DCP in external solution reduced ATR concentrations in rice shoots, especially at low levels $\left(1.0-3.5 \mathrm{mg}^{-1}\right)$, but increased ATR concentrations in rice roots (Fig. 3). Overall, the results of ATR in ATR + CP + DCP mixture systems do not show a general consistency with those in ATR-alone systems, as the ATR + CP + DCP mixture exhibited different phytotoxicities compared to ATR-alone. In plant uptake of chemicals (contaminants) from water, the ratio of chemical concentration in plants to that in external water is termed the "bioconcentration factor" (BCF). It has been recognized that the attainment of full equilibrium for many chemicals between live plants and external water may be difficult with given exposure times [24]. This is because the dissipation and transformation processes of chemicals in plants (e.g., volatilization, metabolism and formation of bound residues) may often outweigh the uptake process. Thus, $\mathrm{BCF}_{\mathrm{a}}$, the apparent $\mathrm{BCF}$, is commonly used to describe the plant accumulation potential when the plant uptake reaches
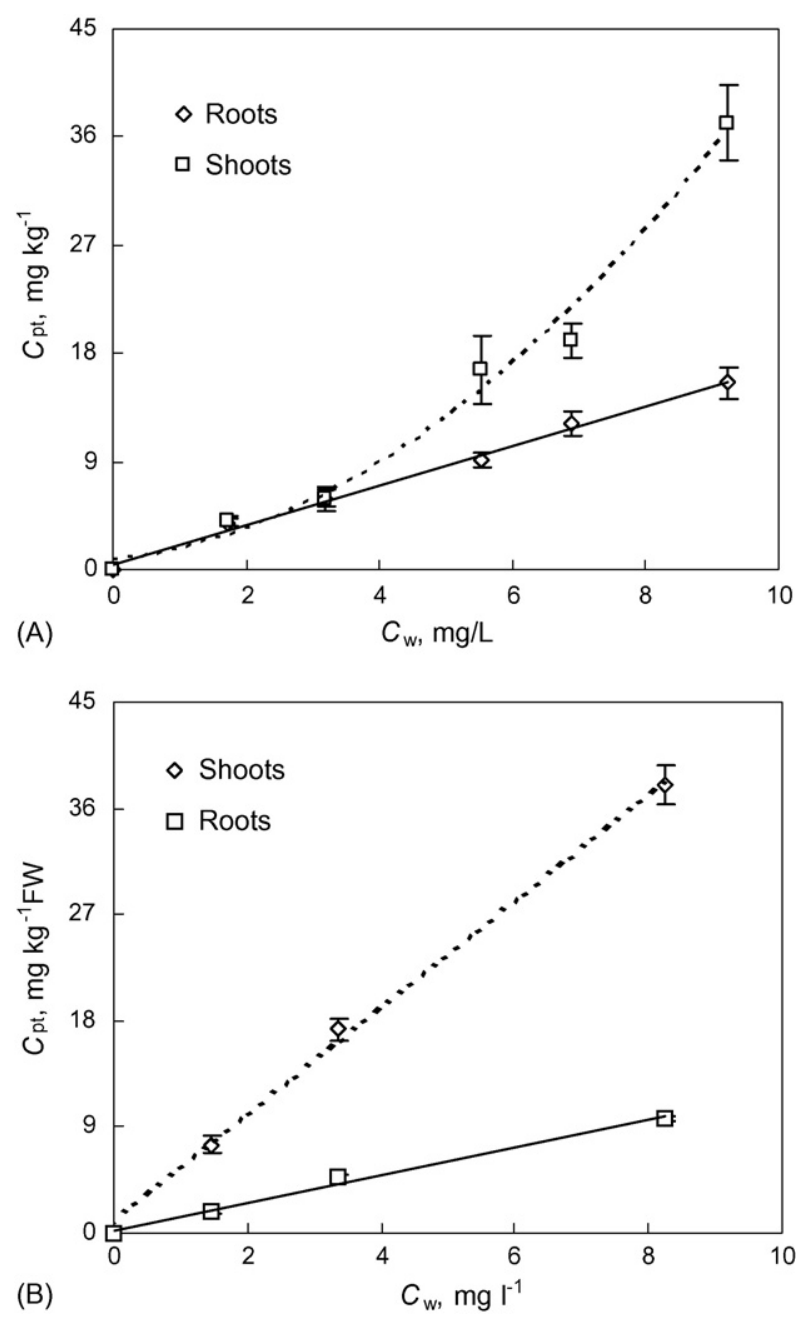

Fig. 3. Uptake of ATR by rice seedlings as a function of ATR concentration in nutrient solution (experiments 1 and 2). (A) ATR as a component in ATR + CP + DCP mixtures; (B) ATR alone. Each point is the mean of four replicates. Error bars represent S.E. 
a plateau with time [22]. The effects of exposure time on plant uptake results from experiment 3, as illustrated in Fig. 1, indicated that the ATR uptake by rice seedlings reached a plateau in about $48 \mathrm{~h}$. From experiments $1-6$, the $\mathrm{BCF}_{\mathrm{a}}$ values of ATR with roots, shoots, and whole seedlings, in which seeding roots were exposed to different levels of ATR alone and ATR-CP-DCP mixtures and to different exposure periods, are calculated and listed in Table 4.

At low ATR + CP + DCP mixture levels (Table 4), the observed $\mathrm{BCF}_{\mathrm{a}}$ or $\alpha_{\mathrm{pt}}$ values for ATR with plant roots increased by about $80 \%$ compared to the corresponding values with ATR alone. The reason for this increase is not known. It is speculated that $\mathrm{CP}$ and DCP in roots reduces the ATR degradation. In contrast, the ATR $\mathrm{BCF}_{\mathrm{a}}$ or $\alpha_{\mathrm{pt}}$ values with plant shoots decreased by about $54 \%$, due possibly to interference of $\mathrm{CP}$ and DCP with the ATR-metal binding capability in shoots. Over the low mixed CP-DCP-ATR levels, the amount of water transpired decreased only by a small extent (relative the control species), and the plant growth was inhibited only slightly by the mixed contaminants relative to that of the control species.

At high ATR + CP + DCP mixture levels, the $\mathrm{BCF}_{\mathrm{a}}$ and $\alpha_{\mathrm{pt}}$ values of ATR with plant roots decreased significantly relative to those at low exposure levels, with the former values being comparable with those in ATR-alone systems, as shown in Table 5. The marked decreases in $\mathrm{RCF}_{\mathrm{a}}$ and $\alpha_{\mathrm{pt}}$ with roots are closely related to the enhanced toxicities of the mixed contaminants, as manifested by a large decline in plant transpiration rate $(G)$ (from $7-8 \mathrm{~g} \mathrm{~g}^{-1}$ down to $\left.3.7-5.2 \mathrm{~g} \mathrm{~g}^{-1}\right)$. The $\mathrm{BCF}_{\mathrm{a}}$ and $\alpha_{\mathrm{pt}}$ values of ATR with shoots at high mixture levels showed an apparent increase relative to those at low mixture levels; moreover, the plant shoots exhibited a clear withering sign during the second day of the exposure and the plant transpiration was found to be nearly at cease $\left(G<1.0 \mathrm{~g} \mathrm{~g}^{-1}\right)$. The apparent increase in $\mathrm{BCF}_{\mathrm{a}}$ and $\alpha_{\mathrm{pt}}$ of ATR results essentially from a significant loss of shoot water content, which creates an apparent increase in calculated $\mathrm{BCF}_{\mathrm{a}}$ and $\alpha_{\mathrm{pt}}$ values (by Eq. (1)) based on the organic and water contents of the control seedlings. In other words, the actual $\left[f_{\mathrm{pw}}+f_{\mathrm{pom}} K_{\mathrm{pom}}\right]$ value for withered shoots would be much greater than that for the control seedlings that was used for determining the $\mathrm{BCF}_{\mathrm{a}}$ and $\alpha_{\mathrm{pt}}$ values. Thus, the calculated $\mathrm{BCF}_{\mathrm{a}}$ and $\alpha_{\mathrm{pt}}$ values for ATR at high mixture levels do not reflect true enhancement of the shoot uptake.

\section{Conclusion}

The effects of exposure time on uptake of ATR alone from nutrient solution by rice seedlings indicate that the uptake reaches an apparent constant level in about $48 \mathrm{~h}$. This finding is consistent with the observation that the BCF values of ATR with both roots and shoots with 48,96 , and $240 \mathrm{~h}$ exposure periods are relatively comparable in magnitude. Analyses of the ATR uptake with rice seedlings by use of the partition-limited model using the measured plant composition and respective ATR partition coefficients indicate that the ATR levels $\left(\right.$ or $\mathrm{BCF}_{\mathrm{a}}$ ) with roots after $48 \mathrm{~h}$ exposure are only about one-third of the equilibrium values, due possibly to the rapid degradation of ATR in roots. In contrast, the ATR levels (or $\mathrm{BCF}_{\mathrm{a}}$ ) with shoots are higher than the calculated partition limits, due presumably to ATR binding with active metals in shoots in addition to its partition with organic matter. For ATR uptake from mixtures of ATR, CP, and DCP, the results vary with the mixture level. At low mixture levels, the ATR $\mathrm{BCF}_{\mathrm{a}}$ with roots are enhanced, indicating the improved stability of ATR in the mixture, while the $\mathrm{BCF}_{\mathrm{a}}$ with shoots is decreased, due likely to the interference of $\mathrm{CP}$ and DCP with the ATR metal binding. At high mixture levels, the observed $\mathrm{BCF}_{\mathrm{a}}$ values with roots and shoots are highly complicated by the enhanced mixture toxicity, and the data do not show a general agreement with those at low single-ATR and mixture levels.

\section{Acknowledgements}

This study was financially supported by the Ministry of Science and Technology (2002CB410808) and the Chinese Academy of Sciences (KZCX3-SW-431 and the Hundred Talent Program).

\section{References}

[1] E.P. Lichtenstein, Insecticidal residues in various crops grown in soils treated with abnormal rates of aldrin and heptachlor, J. Agric. Food Chem. 8 (1960) 448-451.

[2] R.L. King, N.A. Clark, R.W. Hemken, Distribution, movement, and persistence of heptachlor and its epoxide in alfalfa plants and soil, J. Agric. Food Chem. 14 (1966) 62-65.

[3] A. Walker, Availability of atrazine to plants in different soils, Pest Sci. 3 (1972) 139-148.

[4] G.G. Briggs, R.H. Bromilow, A.A. Evans, Relationships between lipophilicity and root uptake and translocation of non-ionised chemicals by barley, Pest Sci. 13 (1982) 495-504.

[5] P. Weiss, Vegetation/soil distribution of semivolatile organic compounds in relation to their physicochemical properties, Environ. Sci. Technol. 34 (2000) 1707-1714.

[6] C.T. Chiou, G. Sheng, M. Manes, A partition-limited model for the plant uptake of organic chemicals from soil and water, Environ. Sci. Technol. 35 (2001) 1437-1444.

[7] S. Trapp, Plant uptake and transport model for neutral and ionic chemicals, Environ. Sci. Pollut. Res. 11 (2004) 33-39.

[8] Y. Gao, L. Zhu, W. Ling, Validation of the partition-limited model for plant uptake of organic chemicals from soil and water, Sci. Tot. Environ. 336 (2005) 171-182.

[9] R.H. Bromilow, K. Chamberlain, Principles governing uptake and transport of chemicals, in: S. Trapp, J.C. McFarland (Eds.), Plant Contamination: Modeling and Simulation of Organic Chemical Processes, Lewis Publishers, Boca Raton, FL, 1995, pp. 38-68.

[10] J. Ren, K. Jiang, Atrazine and its degradation products in surface and ground waters in Zhangjiakou District, China, Chin. Sci. Bull. 47 (2002) 1612-1615.

[11] M. Gfrerer, T. Wenzl, X. Quan, B. Platzer, E. Lankmayr, Occurrence of triazines in surface and drinking water of Liaoning Province in Eastern China, J. Biochem. Biophys. Meth. 53 (2002) 217-228.

[12] T.E. McKone, K.T. Bogen, Predicting the uncertainties in risk assessment, Environ. Sci. Technol. 25 (1991) 1674-1681.

[13] B.L. Finley, D.A. Mayhall, P.K. Scott, Development of a standard soil-toskin adherence probability density function for use in Monte Carlo analysis of dermal exposure, Risk Anal. 14 (1994) 555-569.

[14] J.G. Gu, Y.Z. Fan, J.D. Gu, Biodegradability of Atrazine, Cyanazine and Dicamba under methanogenic condition in three soils of China, Chemosphere 52 (2003) 1515-1521.

[15] T.B. Hayes, A. Collins, M. Lee, M. Mendoza, N. Noriega, A.A. Stuart, A. Vonk, Hermaphroditic, demasculinized frogs after exposure to the 
herbicide atrazine at low ecologically relevant doses 99 (2002) 54765480.

[16] E. Bacci, D. Calamari, G. Gaggi, M. Vighi, Bioconcentration of organic chemical vapors in plant leaves: experimental measurement and correlation, Environ. Sci. Technol. 24 (1990) 885-889.

[17] Y.G. Zhu, G. Shaw, A.F. Nisbet, B.T. Wilkins, Effect of external potassium on compartmentation and flux characteristics of radiocaesium in intact spring wheat roots, Ann. Bot. 84 (1999) 644-659.

[18] C.L. Trostle, P.R. Bloom, D.L. Allan, HEDTA-nitrilotriacetic acid chelatorbuffered nutrient solution for zinc deficiency evaluation in rice, Soil Sci. Soc. Am. J 65 (2001) 385-390.

[19] Y.H. Su, Y.G. Zhu, Influence of lead on atrazine uptake by rice (Oryza sativa L.) seedlings from nutrient solution, Environ. Sci. Pollut. Res. 12 (2005) 21-27.
[20] M. Martin, A. Hagege, J.P. Brunette, M. Leroy, Use of synergistic extraction for the study of atrazine/metal interactions, Anal. Chim. Acta 373 (1998) 161-165.

[21] Z. Meng, W.R. Carper, Effects of hydration on the molecular structure of metal ion-atrazine dimer complexes: a MOPAC (PM3) study, J. Mol. Struct. (Theochem.) 531 (2000) 89-98.

[22] H. Li, G.Y. Sheng, W.T. Sheng, O.Y. Xu, Uptake of trifluralin and lindane from water by ryegrass, Chemosphere 48 (2002) 335341.

[23] S. Trapp, M. Matthies, I. Scheunert, E.M. Topp, Modeling the bioconcentration of organic chemicals in plants, Environ. Sci. Technol. 24 (1990) $1246-1252$.

[24] J.G. Burken, J.L. Schnoor, Uptake and metabolism of atrazine by poplar trees, Environ. Sci. Technol. 31 (1997) 1399-1406. 